\title{
OBSERVATIONS ON THE ANTIOXIDANT ACTIVITY OF NOVEL DIHYDROXYFUMARIC ACID DERIVATIVES
}

\author{
N. Secara, Gh. Duca, L. Vlad, F. Macaev* \\ Institute of Chemistry of the Academy of Sciences of Moldova, \\ Academy str. 3, MD-2028, Chisinau, Moldova \\ Tel+373-22-739-754, Fax+373-22-739-954, E-mail: flmacaev@cc.acad.md
}

\begin{abstract}
The paper describes the syntheses of new derivatives of dihydroxyfumaric acid and investigations of their antioxidant activities using the DPPH method.
\end{abstract}

Keywords: dihydroxyfumaric acid derivatives, DPPH test, antioxidant activity.

\section{Introduction}

The interest in plant metabolites as sources of antioxidants appeared a long time ago. One of the leaders, due to its potential, in the series of natural reductons is the dihydroxyfumaric acid $\mathbf{1}$ [1].

The dihydroxyfumaric acid $\mathbf{1}$ proved to be an efficient reducing compound in several applications, and has been suggested as an intermediate species in the biosynthesis of sugars, uronic acids, and vitamin C [2,3]. DHF was observed to improve wine taste and flavor, leaving out turbidity and inhibiting catechol and phenol oxidation [4]. Also, DHF is used as a disinfectant in contact lenses, in treated municipal sewage or effluents from paper or food-processing industries, as color destabilizing in cleaning products, as an ingredient in highly efficient tobacco smoke filter [5-7]. Maleic acids and the DHF o-acetyl derivatives are used as analgesic and antipyretic drugs [8].

Also, dihydroxyfumarate proved to be a very efficient inhibitor of N-nitrosamines formation in model systems [9], in vitro [10] and in vivo [11].

Due to its structure, very similar to that of ascorbic acid, bearing two hydroxyl groups at vicinal carbons, linked by a double bond, dihydroxyfumaric acid $\mathbf{1}$ is a good radical scavenger and has high antioxidant properties. However, due to very high reaction rates between dihydroxyfumaric acid $\mathbf{1}$ and free radicals, there is very little data in the literature concerning the kinetic investigation of such reactions.

A perspective direction of obtaining new compounds with mentioned above properties is the synthetic transformation of known metabolites.

\section{Results and discussion}

Previously it was shown that compound $\mathbf{1}$, having in its structure carboxyl, hydroxyl and olefin fragments can be used to create porphyrinic macrocycles or pyrimidines [12,13]. However, despite the obvious progress in this direction, the chemistry of dihydroxyfumaric acid $\mathbf{1}$, remains a poorly studied area in many aspects. Among the works on modifying dihydroxyfumaric acid $\mathbf{1}$ there is limited data on the synthesis of aminated derivatives, including with a heterocyclic fragment [14].

Creation of new compounds based on the natural dihydroxyfumaric acid 1, the search for new synthons for targeted synthesis and study of the relationship "structure-property" seem an actual task, to which is devoted this work.

\subsection{Design and development of novel dihydroxyfumaric acid derivatives}

In developing synthetic approaches to obtaining new substances we took into account advances regarding the transformation dihydroxyfumaric acid $\mathbf{1}$, among which there were no synthesis of benzimidazole (Scheme 1). They may be obtained as a result of the interaction of o-phenylenediamine with dihydroxyfumaric acid $\mathbf{1}$. By adjusting the reactants ratio it is possible to synthesize mono-and bisbenzimidazoles. An alternative approach to symmetric and not symmetric congeners can be the selective amidation reaction of dihydroxyfumaric acid $\mathbf{1}$. The choice of substrates is, above all, due to the practical interest, which is manifested in the development of methods for the synthesis of the corresponding derivatives of dihydroxyfumaric acid 1 , as well as to the interest in the chemical processes in terms of forming the desired products.

Nitrogen containing derivatives of dihydroxyfumaric acid $\mathbf{1}$ may open new possibilities in organic synthesis: selecting of appropriate combinations of substituents may allow adjusting the polarity in wide ranges, the solvating ability, catalytic properties and thereby influence the depth and selectivity of the reaction. Data of this study are shown below. 
Scheme 1<smiles></smiles><smiles>CCCCNC(=O)C(O)=C(O)ON</smiles><smiles>CCCCCCC=C(O)C(=O)O</smiles><smiles>O/C(=C(/O)c1nc2ccccc2[nH]1)c1nc2cc[R]cc2[nH]1</smiles><smiles>C1CCC1</smiles><smiles>[R]NOC(O)=C(O)C(=O)O</smiles><smiles>CCNOC(O)=C(O)C(=O)NCC</smiles><smiles>C1=CC=C1</smiles><smiles>[R]NOC(O)=C(O)C(=O)N[R]</smiles>

The dihydroxyfumaric acid $\mathbf{1}$ was first identified (as the trans isomer of the dihydroxymaleinic acid) in the 1950's [15]. Few reports are published concerning the chemistry of DHF was, which is rather surprising considering that research was strongly supported during last few decades, and novel technologies were introduced and applied to improve productivity. DHF proved to be an efficient reducing compound in several applications, and has been suggested as an intermediate species in the biosynthesis of sugars, uronic acids, and vitamin C [2]. Moreover, the DHF o-acetyl derivatives are used as analgesic and antipyretic drugs [8].

The interest in the mechanism of oxidation and isomerisation of trans $\mathbf{1}$ and cis-enediols 4 prompted us to attempt the preparation of different isomers in this series.

\section{Scheme 2}

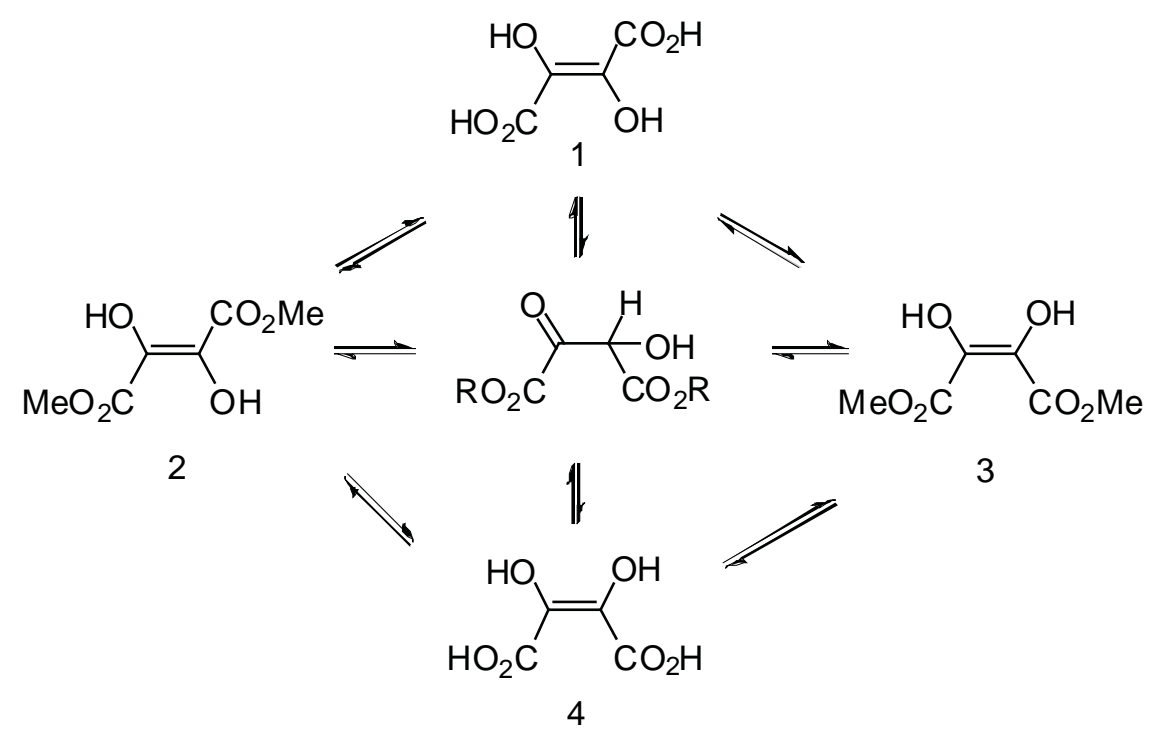

It is known that methylation of dihydroxyfumaric acid $\mathbf{1}$ can be realized via action of the $\mathrm{MeOH} /$ acids or diazomethane. In both cases, the configuration of esters $\mathbf{2}$ is trans $[15,16]$.

We performed a new esterification of DHF with methanol under the action of trimethylsilyl chloride. 
In this case, the ester had m.p. $149^{\circ} \mathrm{C}$ although $[15,16]$ give $173^{\circ} \mathrm{C}$. Our registered Infrared spectra were very similar with literature data for compound 2. It is worth mentioning one important difference in the shift of the ester band (trans- at $1677.8 \mathrm{~cm}^{-1}$ cis - at $1670.7 \mathrm{~cm}^{-1}$ ), the absence of any differences in $\mathrm{C}=\mathrm{C}$ bands and a small difference of the shift of the $\mathrm{OH}$ band at $3164.5 \mathrm{~cm}^{-1}$ and at $3168.2 \mathrm{~cm}^{-1}$, respectively.

In ${ }^{1} \mathrm{H}$ NMR spectrum of compound 2 the signal of both methyl groups are located in characteristic region for methyl esters (at $3.94 \mathrm{ppm}$ ). Moreover, the signal of the hydroxyl groups was observed as singlet at $9.36 \mathrm{ppm}$. In the mass spectrum of the investigated compound, the mass of the molecular ion $M^{+}$is 176.03 . These data, in combination with the data of elemental analysis specify the structure $\mathbf{2}$.

The conversion of esters to amides is a useful reaction, and different amides can be prepared this way from appropriate amine. The reaction is particularly useful because ester $\mathbf{2}$ is easily prepared, even in cases where the corresponding acyl halide or anhydride are not. Although more studies have been devoted to the mechanism of acylation of amines with esters than with other reagents, the mechanistic details are not yet entirely clear.

Under the normal alkaline conditions, the reaction is base-catalyzed, indicating that a proton is being transferred in the rate-determining step and that two molecules of amine are involved.

Heating of the diester $\mathbf{2}$ in aniline solution during two hours leads to the formation of the sole product, its structure was determined on the basis of spectral data. The specific feature of ${ }^{1} \mathrm{H}$ NMR spectrum of the investigated compound, in comparison with those for a product 2 , is the presence of two singlet at $3.62 \mathrm{ppm}(\mathrm{OMe}), 7.82 \mathrm{ppm}$ $(\mathrm{OH})$ and signals of aromatic group in region $6.48-7.88 \mathrm{ppm}$. These data are supported by the IR-spectrum having characteristic bands at 1474, 1496, $1595 \mathrm{~cm}^{-1}(\mathrm{Ar}), 1568, \mathrm{~cm}^{-1}(\mathrm{CONH}), 1665 \mathrm{~cm}^{-1}\left(\mathrm{CO}_{2}\right)$. These data, in combination with the results of the elemental analysis, confirm the structure $\mathbf{5}$.

Scheme 3
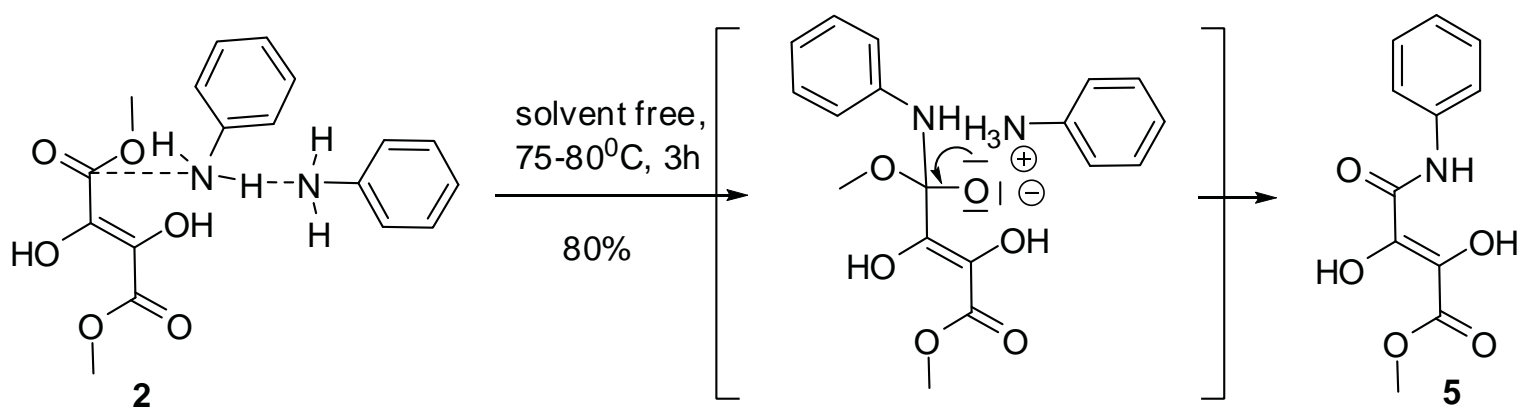

Increasing the reaction time and temperature to the boiling point of aniline didn't lead to the formation of bisanilide. It should be mentioned that the tentative of synthesis of the mixed amide by heating ester 5 with monoethanolamine wasn't successful, either.

An interesting result in the reaction of amidation of diester 2 was obtained when replacing aniline with its nitrogencontaining analogue - 2-aminopyridine (Scheme 4).

\section{Scheme 4}<smiles>COC(=O)/C(O)=C(\O)C(=O)OC</smiles>

2<smiles>Nc1ccccn1</smiles>

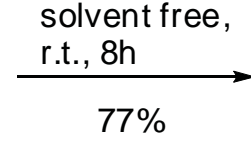

$77 \%$<smiles>O=C(Nc1ccccn1)C(O)=C(O)C(=O)Nc1ccccn1</smiles>

6

A crystalline substance was separated with melting temperature of $145^{\circ} \mathrm{C}$, i.e. four degrees lower than in the case of the initial compound 2. In the IR spectrum of investigated sample, appear the characteristic bands for Py, -CO-NHand $\mathrm{OH}$ groups. In comparison with ${ }^{1} \mathrm{H}$ NMR spectrum of compound 5 the signal of $\mathrm{CO}_{2} \mathrm{Me}$ group was not observed. In the weak area of its ${ }^{13} \mathrm{C}$ NMR spectrum, the seven signals of carbon atoms at 157.32, 148.81, 141.76, 141.20, 138.87, 113.41 and $112.36 \mathrm{ppm}$. These data, in combination with the data of elemental analysis specify the structure $\mathbf{6}$.

Therefore, replacing of the carbon atom in the benzene ring with nitrogen in the initial amine, had a significant influence on the character of the formed compound.

It was mentioned earlier that attempts of synthesizing mixed amides using monoethanol amine and ether $\mathbf{5}$, proved to be unsuccessful. 
If the amidation is carried out at room temperature by using ester 2 and monoethanolamine, the reaction product is bis-amidoalcohol 7.

In its IR-spectrum there are bands characteristic to the amide and hydroxyl groups (see exp.). ${ }^{1} \mathrm{H}$ NMR spectrum of compound 7 contains singlet signal of primary and tertiary hydroxyl groups (in the region 3.3-3.45 and 4.5-5.0 ppm, respectively), quartet (at $3.2 \mathrm{ppm}$ ) and triplet (at $3.44 \mathrm{ppm}$ ) signals of methylene groups, which are completed by the signal of amide proton at $8.57 \mathrm{ppm}$. In the high area of its ${ }^{13} \mathrm{C}$ NMR spectrum two signals of carbon atoms are evidenced (see exp.), which are completed by two signals in the weak area at 154.9 and $160.49 \mathrm{ppm}$. In the mass spectrum of the investigated compound, the mass of the molecular ion $M^{+}$is 234.08 .

\section{Scheme 5}<smiles>COC(=O)/C(O)=C(\O)C(=O)OC</smiles>

2

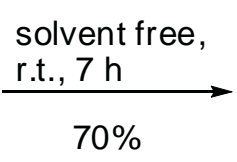<smiles>O=C(NCCO)C(O)=C(O)C(=O)NCCO</smiles>

7

The influence of the nature of homologues of monoethanolamine on the reaction rate and physico-chemical properties of dihydroxymaleinic acid amides was investigated.

Increasing the alkyl radical by one methylene fragment in the initial aminoalcohol gave the decrease of the total output of the reaction, as well as of the melting point from $158-160^{\circ} \mathrm{C}$ to $142-143^{\circ} \mathrm{C}$.

The homologue 8 was spectrally characterized. The presence of an additional methylene group in the structure of compound $\mathbf{8}$, as compared to structure 7 , is demonstrated by the characteristic signal in its ${ }^{1} \mathrm{H}$ NMR spectrum (in the region 1.5-1.61 ppm), which is in accordance with the signal in its ${ }^{13} \mathrm{C}$ NMR spectrum at $32.77 \mathrm{ppm}$. In the mass spectrum of the investigated compound, the mass of the molecular ion $M^{+}$is 262.11 .

\section{Scheme 6}<smiles>COC(=O)/C(O)=C(\O)C(=O)OC</smiles>

2

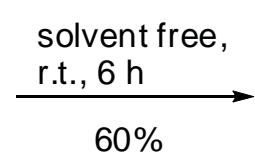<smiles>O=C(NCCCO)C(O)=C(O)C(=O)NCCCO</smiles>

8

The presence of two methyl groups in the $\alpha$-position with respect to the amino group in the initial 2-amino-2methylpropan-1-ol didn't decrease the yield of the target diamide 9. Analogically to the previous synthesis, this reaction was performed at room temperature.

\section{Scheme 7}

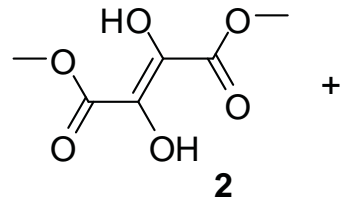<smiles>[R]CC(N)(C[R])C[R]</smiles>

solvent free

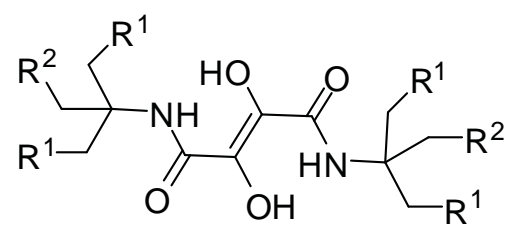

$9 \mathrm{R}^{1}=\mathrm{H}, \mathrm{R}^{2}=\mathrm{OH}(75 \%)$

$10 \mathrm{R}^{1}=\mathrm{OH}, \mathrm{R}^{2}=\mathrm{OH}(69 \%)$

$11 \mathrm{R}^{1}=\mathrm{R}^{2}=\mathrm{H}(70 \%)$

The transformation into the 2-amino-2-(hydroxymethyl)propane-1,3-diol decreased the reactivity of the amine. According to TLC data, only in the case of fusion of initial reagents at $50^{\circ} \mathrm{C}$ the formation of one single product was observed. Following processing of the reaction mass with yield of $69 \%$, was separated $\mathrm{N}^{1}, \mathrm{~N}^{4}$-bis( 1 , 3-dihydroxy2-(hydroxymethyl)propan-2-yl)-2,3-dihydroxyfumaramide 10, and its structure was proved by spectral and physicochemical methods. Thus, in its ${ }^{1} \mathrm{H}$ NMR spectrum there are multiplet signals of six methylene groups in the region 3.37-3.62 ppm. The signals of six hydroxyl groups are registered in the region from 3.62 to $5.3 \mathrm{ppm}$.

It should be mentioned that the homologue $\mathbf{1 1}$ may be synthesized at room temperature by mixing of tert-butyl 
amine with diester $\mathbf{2}$. In this case, the yield of the reaction product is practically the same with the mentioned above. As opposed to homologue 9, the separated product 11, analogically to compound $\mathbf{1 0}$ represents a crystalline substance.

Following the syntheses of a series of amides of the dihydroxyfumaric acid $\mathbf{1}$, were decided to continue with the synthesis of heterocyclic derivatives.

The benzimidazole nucleus has been of considerable interest since it was noted that benzimidazole inhibits the growth of certain yeasts and bacteria. Such heterocyclic systems can be modified not only by changing the nature and the number of the connecting atoms but by changing the nature of the substituents in the benzimidazole nuclei as well. In literature revealed the fact that a number of bis-benzimidazoles have been reported but apparently none of them have been synthesized from dihydroxyfumaric acid $\mathbf{1}$.

In the present investigation methods were developed to synthesize novel mono and bis-benzimidazoles where the both benzimidazole nuclei are united through their 2-positions either through ethen-1,2-diols.

The benzimidazole was synthesized by hydrochloric acid-catalyzed condensation of the o-phenylenediamine with a dihydroxyfumaric acid 1 an oil bath at $135^{\circ}$ under $\mathrm{N}_{2}$. The same procedure can be used to prepare bis-benzimidazoles by refluxing two moles of diamine with one mole of a dihydroxyfumaric acid 1 in $4 N$ hydrochloric acid.

\section{Scheme 8}

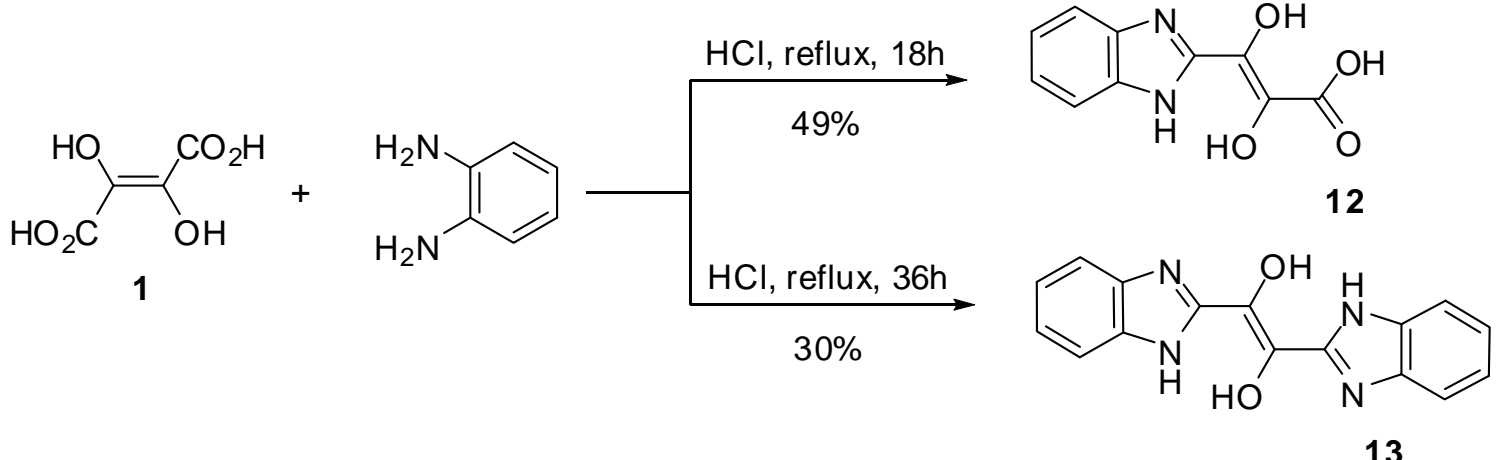

Analytical results of Synthesized Compounds

Table1

\begin{tabular}{|c|c|c|c|c|c|c|}
\hline \multirow[t]{2}{*}{$\begin{array}{l}\text { Compound/ } \\
\text { Molecular formula }\end{array}$} & \multirow[t]{2}{*}{$\begin{array}{l}\text { Aggregation/ } \\
\text { Color/ M.p. }{ }^{\circ} \mathrm{C}\end{array}$} & \multirow[t]{2}{*}{$\begin{array}{l}\text { Method } / \\
\text { Yield (\%) }\end{array}$} & \multirow[t]{2}{*}{$\begin{array}{l}\text { IR (Nujol) } \\
v, \mathrm{~cm}^{-1}\end{array}$} & \multicolumn{3}{|c|}{$\begin{array}{c}\text { Elemental analysis } \\
\text { Requires /Found }\end{array}$} \\
\hline & & & & $\mathrm{C}$ & $\mathrm{H}$ & $\mathrm{N}$ \\
\hline $\begin{array}{c}2 \\
\mathrm{C}_{6} \mathrm{H}_{8} \mathrm{O}_{6}\end{array}$ & $\begin{array}{l}\text { Solid/ } \\
\text { White/ } \\
149^{\circ} \mathrm{C}\end{array}$ & $\mathrm{A} / 66$ & $\begin{array}{l}691,771,879,893,1021,1184, \\
1213,1243,1300,1396,1442, \\
1460,1516,1671,2822,2887, \\
2963,3168,3376 .\end{array}$ & $\begin{array}{l}40.92 / \\
40.79\end{array}$ & $\begin{array}{l}4.58 / \\
4.98\end{array}$ & - \\
\hline$\stackrel{5}{\mathrm{C}_{11} \mathrm{H}_{11} \mathrm{NO}_{5}}$ & $\begin{array}{c}\text { Solid/ } \\
\text { Yellow/ } \\
202-203^{\circ} \mathrm{C}\end{array}$ & $\mathrm{C} / 80$ & $\begin{array}{l}778,794,868,902,958,1003, \\
1029,1078,1143,1162,1193, \\
1223,1240,1317,1330,1437, \\
1475,1497,1558,1595,1665, \\
1729,3301,3337 .\end{array}$ & $\begin{array}{l}55.70 / \\
55.56\end{array}$ & $\begin{array}{l}4.67 / \\
4.88\end{array}$ & $\begin{array}{l}5.90 / \\
6.04\end{array}$ \\
\hline$\frac{6}{\mathrm{C}_{14} \mathrm{H}_{12} \mathrm{~N}_{4} \mathrm{O}_{4}}$ & $\begin{array}{c}\text { Oil/ } \\
\text { Yellow }\end{array}$ & $\mathrm{A} / 77$ & $\begin{array}{l}724,770,848,867,938,989, \\
1022,1051,1100,1151,1162, \\
1242,1299,1329,1382,1434, \\
1485,1522,1547,1572,1589, \\
1629,1668,2011,2712,3081, \\
3147,3310 .\end{array}$ & $\begin{array}{l}56.00 / \\
56.20\end{array}$ & $\begin{array}{l}4.03 / \\
4.16\end{array}$ & $\begin{array}{l}18.66 / \\
16.78\end{array}$ \\
\hline $\begin{array}{c}7 \\
\mathrm{C}_{8} \mathrm{H}_{14} \mathrm{~N}_{2} \mathrm{O}_{6}\end{array}$ & $\begin{array}{l}\text { Solid/ } \\
\text { Colourless/ } \\
158-160^{\circ} \mathrm{C}\end{array}$ & $\mathrm{A} / 70$ & $\begin{array}{l}660,745,761,825,1013,1035, \\
1055,1106,1205,1240,1299, \\
1315,1391,1445,1476,1534, \\
1651,2824,2881,2941,2985, \\
3287 .\end{array}$ & $\begin{array}{l}41.03 / \\
41.22\end{array}$ & $\begin{array}{l}6.03 / \\
5.95\end{array}$ & $\begin{array}{l}11.96 / \\
13.79\end{array}$ \\
\hline
\end{tabular}




\begin{tabular}{|c|c|c|c|c|c|c|}
\hline$\underset{\mathrm{C}_{10} \mathrm{H}_{18} \mathrm{~N}_{2} \mathrm{O}_{6}}{\mathbf{8}}$ & $\begin{array}{c}\text { Solid/ } \\
\text { Colourless/ } \\
142-143^{\circ} \mathrm{C}\end{array}$ & $\mathrm{A} / 60$ & $\begin{array}{l}745,761,822,862,913,943, \\
1029,1046,1072,1113,1201, \\
1241,1252,1300,1312,1324, \\
1361,1441,1476,1532,1650, \\
1740,2859,2893,2933,2952, \\
2981,3067,3300,3336,3400 .\end{array}$ & $\begin{array}{l}45.80 / \\
45.99\end{array}$ & $\begin{array}{l}6.92 / \\
6.73\end{array}$ & $\begin{array}{l}10.68 / \\
10.49\end{array}$ \\
\hline $\begin{array}{c}9 \\
\mathrm{C}_{12} \mathrm{H}_{22} \mathrm{~N}_{2} \mathrm{O}_{6}\end{array}$ & Oil/Yellow & $\mathrm{A} / 75$ & $\begin{array}{l}739,761,769,791,846,860, \\
901,934,977,1011,1080, \\
1121,1183,1206,1228,1228, \\
1259,1294,1319,1374,1403, \\
1454,1487,1511,1546,1560, \\
1588,1637,1678,1742,2115, \\
2316,2428,2559,2647,2738, \\
2839,2909,2974,3375 .\end{array}$ & $\begin{array}{l}49.65 / \\
49.85\end{array}$ & $\begin{array}{l}7.64 / \\
7.77\end{array}$ & $\begin{array}{l}9.65 / \\
9.61\end{array}$ \\
\hline$\underset{\mathrm{C}_{12}}{\mathbf{1 0}} \mathrm{H}_{22} \mathrm{~N}_{2} \mathrm{O}_{10}$ & $\begin{array}{l}\text { Solid/ } \\
\text { Colourless/ } \\
142-143{ }^{\circ} \mathrm{C}\end{array}$ & $\mathrm{B} / 69$ & $\begin{array}{l}683,773,825,870,909,984, \\
1023,1042,1119,1179,1227, \\
1262,1279,1368,1383,1425, \\
1461,1515,1663,1735,2887, \\
2944,3252,3336 .\end{array}$ & $\begin{array}{l}40.68 / \\
40.49\end{array}$ & $\begin{array}{l}6.26 / \\
6.41\end{array}$ & $\begin{array}{l}7.91 / \\
8.02\end{array}$ \\
\hline$\frac{11}{\mathrm{C}_{12} \mathrm{H}_{22} \mathrm{~N}_{2} \mathrm{O}_{4}}$ & $\begin{array}{c}\text { Solid/ } \\
\text { Colourless/ } \\
120-122^{\circ} \mathrm{C}\end{array}$ & $\mathrm{A} / 70$ & 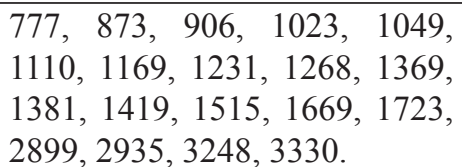 & $\begin{array}{l}55.80 / \\
55.96\end{array}$ & $\begin{array}{l}8.58 / \\
8.77\end{array}$ & $\begin{array}{l}10.84 / \\
11.03\end{array}$ \\
\hline $\begin{array}{c}12 \\
\mathrm{C}_{10} \mathrm{H}_{8} \mathrm{~N}_{2} \mathrm{O}_{4}\end{array}$ & $\begin{array}{l}\text { Solid/ } \\
\text { Brown/ } \\
250^{\circ} \mathrm{C} \mathrm{dec} \text {. }\end{array}$ & $\mathrm{C} / 49$ & $\begin{array}{l}672,754,831,952,1048,1135, \\
1310,1463,1490,1525,1610, \\
1677,2299,2577,2791,3341, \\
3737 .\end{array}$ & $\begin{array}{l}54.55 / \\
54.38\end{array}$ & $\begin{array}{l}3.66 / \\
3.78\end{array}$ & $\begin{array}{l}12.72 / \\
12.71\end{array}$ \\
\hline $\begin{array}{c}13 \\
\mathrm{C}_{16} \mathrm{H}_{12} \mathrm{~N}_{4} \mathrm{O}_{2}\end{array}$ & $\begin{array}{c}\text { Solid/ } \\
\text { Brown/ } \\
250^{\circ} \mathrm{C} \mathrm{dec} .\end{array}$ & $\mathrm{C} / 30$ & $\begin{array}{l}726,754,838,893,953,1049, \\
1079,1132,1149,1238,1260, \\
1368,1396,1449,1480,1527, \\
1570,1618,1643,1686,1777, \\
2803,2989,3031,3118,3306 .\end{array}$ & $\begin{array}{l}65.75 / \\
65.91 /\end{array}$ & $\begin{array}{l}4.14 / \\
4.13\end{array}$ & $\begin{array}{l}19.17 / \\
18.88\end{array}$ \\
\hline
\end{tabular}

${ }^{a}$ Method: $\mathbf{A}$ - Reaction at room temperature; B - Reaction at $50-55^{\circ} \mathrm{C}$; C-Reaction at $75-80^{\circ} \mathrm{C}$. D - Reaction at $125-$ $135^{\circ} \mathrm{C}$.

Due to the fact that the initial dihydroxyfumaric acid possesses maximal absorption at $295 \mathrm{~nm}$ ( $\varepsilon=7100$ in aqueous methanol) it was decided to register the spectra of the synthesized compounds in $70 \%$ aqueous methanol in order to determine the correlation between the UV absorption and the structure of the molecule and the antioxidant activity (see Table 2).

UV-Absorption of Synthesized Compounds

\begin{tabular}{cccc}
\hline No. & Compound & $\boldsymbol{\lambda}_{\text {max }}, \mathbf{n m}$ & $\boldsymbol{\varepsilon}$ \\
\hline 1 & $\mathbf{2}$ & 300 & 3500 \\
2 & $\mathbf{5}$ & 285 & 10365 \\
3 & $\mathbf{6}$ & 299 & 9825 \\
4 & 7 & 215 & 18900 \\
5 & $\mathbf{8}$ & 214 & 9965 \\
6 & $\mathbf{9}$ & 211 & 6245 \\
7 & $\mathbf{1 0}$ & 210 & 7305 \\
8 & $\mathbf{1 1}$ & 296 & 315 \\
9 & $\mathbf{1 2}$ & 267 & 7960 \\
\hline
\end{tabular}


Substitution of the carboxyl group with the ester group shifts absorption towards shorter wavelengths. The bathochromic shift is registered for all amides and benzimidazoles. The value $\boldsymbol{\lambda}_{\max }$ for tert-butylamides $\mathbf{1 1}$ is most equal to that for acid 1, whereas the structural differences of these substances produce almost 20 fold changes in $\boldsymbol{\varepsilon}_{\text {max }}$ : from 7100 to 315 . Saturated substituents, which include other heteroatoms such as oxygen and nitrogen, contain nonbonding electrons besides the $\sigma$-electrons. Amides 7-10 with a free hydroxyl group absorb at wavelengths less than the original ether 2. Increasing the length of the carbon skeleton, or substitution of two hydrogen atoms on the methyl or carbinol group in compound 7 leads towards longer wavelengths in the chain of $\mathbf{7} \rightarrow \mathbf{8} \rightarrow \mathbf{9} \rightarrow \mathbf{1 0}$. The mean values of $\boldsymbol{\lambda}_{\max }$ of these three types of compounds listed in Table 2 indicate their decrease in the same sequence.

As expected, the absorption of aromatic and heterocyclic compounds of the investigated series are different from saturated derivatives of linear structure. The values $\lambda_{\max }$ of compounds $\mathbf{5 , 6 , 1 2}$ and $\mathbf{1 3}$ are higher than those of the discussed above substances, except for compound 11. There wasn't noticed a correlation between the values $\lambda_{\max }$ and $\varepsilon_{\max }$.

It should be noted that probably such generalizations cannot be used in all cases, because these data apply only to alicyclic derivatives of acid $\mathbf{1}$.

Next, our attention has been focused on the study of antioxidant properties of synthesized compounds.

It was determined that all amides of alicyclic structure showed a weak desired activity (see Table 3).

The presence of nitrogen atoms in the molecules of compounds $\mathbf{6}$ and $\mathbf{1 3}$ has a negative effect on the antioxidant activity in comparison with the activity of anilide 5 or mono-benzimidazole 12. Bis-benzimidazole $\mathbf{1 3}$ showed antioxidant activity at the same level as the ether $\mathbf{2}$. The highest antioxidant activity was exhibited by mono-benzimidazole $\mathbf{1 2}$.

\section{Antioxidant properties of Synthesized Compounds}

Table 3

\begin{tabular}{cc}
\hline Compound & $\begin{array}{c}\text { Number of DPPH molecules } \\
\text { reduced by one antioxidant molecule }\end{array}$ \\
\hline $\mathbf{2}$ & 1.07 \\
$\mathbf{5}$ & 0.63 \\
$\mathbf{6}$ & 0.25 \\
$\mathbf{7}$ & 0.02 \\
$\mathbf{8}$ & 0.05 \\
$\mathbf{9}$ & 0.031 \\
$\mathbf{1 0}$ & 0.066 \\
$\mathbf{1 1}$ & 0.009 \\
$\mathbf{1 2}$ & 2.1 \\
$\mathbf{1 3}$ & 1 \\
\hline
\end{tabular}

\section{Summary}

A new method was developed for the synthesis of the dimethyl ether of dihydroxyfumaric acid and its aminated derivatives. The correlation between the structure of the molecule, the UV absorption and the antioxidant activity was investigated.

Increasing the length of the carbon skeleton of the amide fragment, or substitution of two hydrogen atoms with the methyl or carbinol, shifts UV absorption towards longer wavelengths. The mean values of $\lambda_{\max }$ of these three types of derivatives decrease in the same sequence. The presence in the molecules of amides or heterocyclic derivatives of additional nitrogen atoms has a negative effect on the antioxidant activity in comparison with the activity of anilide or mono-benzimidazole. Benzimidazole with a free carboxyl group showed antioxidant activity to two times higher than the ether 2 .

The obtained data suggest that generalizations are not of a general nature and are applicable only to discuss types of acid derivatives 1 .

\section{Experimental methods}

All used solvents were of reagent quality, and all commercial reagents were used without additional purification. Removal of all solvents was carried out under reduced pressure. Analytical TLC plates were Silufol ${ }^{\circledR}$ UV-254 (Silpearl on aluminium foil, Czecho-Slovakia). IR spectra were recorded on a Spectrum 100 FT-IR spectrophotometer (Perkin -Elmer) using the universal ATR sampling accessory. Melting points (uncorrected) were determined on a Boetius apparatus. The mass spectra (ES) were measured on Thermo Scientific Exactive mass spectrometer using Advion Travesra Nanomate automated injection system. ${ }^{1} \mathrm{H}$ and ${ }^{13} \mathrm{CNMR}$ spectra have been recorded for $\left(\mathrm{CD}_{3}\right)_{2} \mathrm{SO} 2-\%$ solution on a "Bruker -Avance III" (400.13 and 100.61 MHz).

UV spectra were recorded on a Perkin Elmer Lambda 25 UV/Vis spectrometer.

Antioxidant activity of investigated compounds was determined according to the method described earlier [17] with 
several modifications. Briefly, DPPH and all other compounds were dissolved in $70 \%$ aqueous methanol, exact initial concentrations were determined using linear regression equations for each compound. Absorbance was read at $217 \mathrm{~nm}$. For each antioxidant, different mollar ratios (MR), expressed as moles of investigated compound per mole of DPPH, were tested. For each MR, the remaining percentage of DPPH at the plateau was determined and graphed, and $\mathrm{EC}_{50}$ was determined as the MR which reduces half of the initial DPPH concentration.

2,3-Dihydroxyfumaric acid, aniline, pyridin-2-amine, 2-aminoethanol, 3-aminopropan-1-ol, 2-amino-2methylpropan-1-ol, 2-amino-2-(hydroxymethyl)propane-1,3-diol and 2-methylpropan-2-amine - reagents from Aldrich Chemical Company.

\section{Synthesis of the dimethyl 2,3-dihydroxyfumarate 2 .}

The mixture of 2,3-dihydroxyfumaric acid 1 (1.48 g, 0.01 mole), $\mathrm{Me}_{3} \mathrm{SlCl}(0.324 \mathrm{~g}, 0.03$ mole) and $5 \mathrm{ml}$ of $\mathrm{MeOH}$ was stirred for 3 days. Excess of $\mathrm{Me}_{3} \mathrm{SlCl}$ and $\mathrm{MeOH}$ was removed in vacuum. Compound 2 was separated as white crystals by precipitation with mixture hexane/ $/ \mathrm{Et}_{2} \mathrm{O}$ and filtration. Yield: $1.16 \mathrm{~g}$. Spectrum ${ }^{1} \mathrm{H}$ NMR: $3.94 \mathrm{~s}(6 \mathrm{H}$, $\left.2 \mathrm{CH}_{3}\right), 9.36 \mathrm{~s}(2 \mathrm{H}, 2 \mathrm{OH}) . \mathrm{MS} m / z 231.0472\left(\mathrm{M}^{+}+\mathrm{Na}\right)$.

\section{Synthesis of the (E)-methyl 2,3-dihydroxy-4-oxo-4-(phenylamino)but-2-enoate 5.}

The mixture of esters $2(1.76 \mathrm{~g}, 0.01 \mathrm{~mole})$ and $2 \mathrm{ml}$ of aniline was stirred at $75-80^{\circ} \mathrm{C}$ for 3 hours. Excess of amine was removed in vacuum. Compound 2 was separated by column chromatography. Yield: $1.90 \mathrm{~g}, 66 \%$. Spectrum ${ }^{1} \mathrm{H}$ NMR: $3.62 \mathrm{~s}\left(3 \mathrm{H}, \mathrm{CH}_{3}\right), 7.82 \mathrm{~s}(2 \mathrm{H}, 2 \mathrm{OH}), 6.48-7.87 \mathrm{~m}(5 \mathrm{H}$, arom).

\section{Synthesis of the 2,3-dihydroxy- $\mathrm{N}^{1}, \mathrm{~N}^{4}$-di(pyridin-2-yl)fumaramide 6 .}

The mixture of esters 2 (1.76 g, 0.01 mole) and pyridin-2-amine $(0.940 \mathrm{~g}, 0.01 \mathrm{~mole})$ was stirred at room temperature for 8 hours. After completion (TLC analysis), the reaction mixture was directly loaded on a silica gel column and eluted with hexane-ethyl acetate to afford the product 6. Yield: $2.31 \mathrm{~g}, 77 \%$. Spectrum ${ }^{1} \mathrm{H}$ NMR: $7.69 \mathrm{br}$ s $(2 \mathrm{H}, 2 \mathrm{OH}), 6.67-7.92 \mathrm{~m}\left(8 \mathrm{H}\right.$, arom). Spectrum ${ }^{13} \mathrm{C}$ NMR: 157.32, 148.81, 141.76, 141.20, 138.87, 113.41, 112.36.

\section{Synthesis of the 2,3-dihydroxy- $\mathrm{N}^{1}, \mathrm{~N}^{4}$-bis(2-hydroxyethyl)fumaramide 7 .}

The mixture of esters $2(1.76 \mathrm{~g}, 0.01 \mathrm{~mole})$ and 2-aminoethanol $(2 \mathrm{ml})$ was stirred at room temperature for 6 hours. After completion (TLC analysis), the excess of 2-aminoethanol was removed in vacuum. Compound 7 was separated as white crystals by crystallization from $\mathrm{EtOH}$ and filtration. Yield: $1.64 \mathrm{~g}, 70 \%$. Spectrum ${ }^{1} \mathrm{H}$ NMR: $3.25 \mathrm{t}$ $\left(4 \mathrm{H}, 2 \mathrm{CH}_{2} \mathrm{~N}, J=6.0\right), 3.44 \mathrm{t}\left(4 \mathrm{H}, 2 \mathrm{CH}_{2} \mathrm{~N}, J=6.0\right), 4.5-4.85 \mathrm{~s}(2 \mathrm{H}, 2 \mathrm{C}=\mathrm{OH}), 8.57 \mathrm{t}(2 \mathrm{H}, 2 \mathrm{NH}, J=4.0)$. Spectrum ${ }^{13} \mathrm{C} \mathrm{NMR:}$ $160.49,154.9,59.68,42.13$. MS $m / z 257.0711\left(\mathrm{M}^{+}+\mathrm{Na}\right)$.

\section{Synthesis of the 2,3-dihydroxy- $\mathrm{N}^{1}, \mathrm{~N}^{4}$-bis(2-hydroxypropyl)fumaramide 8 .}

The mixture of esters $2(1.76 \mathrm{~g}, 0.01 \mathrm{~mole})$ and $2 \mathrm{ml}$ of 3-aminopropan-1-ol was stirred at room temperature for 6 hours. After completion (TLC analysis), the excess of 3-aminopropan-1-ol was removed in vacuum. Compound 8 was separated as white crystals by crystallization from EtOH and filtration. Yield: $1.57 \mathrm{~g}, 60 \%$. Spectrum ${ }^{1} \mathrm{H}$ NMR: 1.56-1.62 $\mathrm{m}\left(4 \mathrm{H}, 2 \mathrm{CH}_{2} \mathrm{CH}_{2} \mathrm{CH}_{2}\right), 3.16-3.25 \mathrm{~m}\left(4 \mathrm{H}, 2 \mathrm{CH}_{2} \mathrm{~N}\right), 3.39-3.42 \mathrm{~m}\left(2 \mathrm{H}, 2 \mathrm{CH}_{2} \mathrm{OH}\right), 3.5-4.0 \mathrm{br} \mathrm{s}(4 \mathrm{H}, 4 \mathrm{OH}), 8.7 \mathrm{t}(2 \mathrm{H}, 2$ $\mathrm{NH}, J=4.0)$. Spectrum ${ }^{13} \mathrm{C}$ NMR: $172.18,160.47,59.18,37.01,32.77$. MS $m / z 285.1041\left(\mathrm{M}^{+}+\mathrm{Na}\right)$.

\section{Synthesis of the 2,3-dihydroxy- $\mathrm{N}^{1}, \mathrm{~N}^{4}$-bis(1-hydroxy-2-methylpropan-2-yl)fumaramide 9 .}

The mixture of esters 2 (1.76 g, 0.01 mole) and 2-amino-2-methylpropan-1-ol ( $0.890 \mathrm{~g}, 0.01 \mathrm{~mole})$ was stirred at room temperature for 12 hours. After completion (TLC analysis), the reaction mixture was directly loaded on a silica gel column and eluted with hexane-ethyl acetate to afford the product 9. Yield: $2.18 \mathrm{~g}, 75 \%$. Spectrum ${ }^{1} \mathrm{H}$ NMR: 1.06 s $\left(12 \mathrm{H}, 4 \mathrm{CH}_{3}\right), 3.25 \mathrm{~s}\left(4 \mathrm{H}, 2 \mathrm{CH}_{2}\right), 4.7-5.2$ br s $(4 \mathrm{H}, 4 \mathrm{OH}), 7.81 \mathrm{~s}(2 \mathrm{H}, 2 \mathrm{NH})$. Spectrum ${ }^{13} \mathrm{C}$ NMR: 164.76, 159.86, $69.29,53.83,24.82$.

Synthesis of the $\mathbf{N}^{1}, \mathbf{N}^{4}$-bis(1,3-dihydroxy-2-(hydroxymethyl)propan-2-yl)-2,3-dihydroxyfumaramide10.

The mixture of esters 2 (1.76 g, 0.01 mole) and 2-amino-2-(hydroxymethyl)propane-1,3-diol (1.21 g, $0.01 \mathrm{~mole}$ ) was stirred at $50-55^{\circ} \mathrm{C}$ for 12 hours. After completion (TLC analysis), compound 10 was separated as white crystals by crystallization from $\mathrm{MeOH}$ and filtration. Yield: $2.44 \mathrm{~g}, 69 \%$. Spectrum ${ }^{1} \mathrm{H}$ NMR: $3.29-3.62 \mathrm{~m}\left(12 \mathrm{H}, 6 \mathrm{CH}_{2}\right), 4.0-5.3 \mathrm{br} \mathrm{s}$ (8H, $8 \mathrm{OH}), 7.79 \mathrm{~s}(2 \mathrm{H}, 2 \mathrm{NH})$. Spectrum ${ }^{13} \mathrm{C}$ NMR: 175.3, 159.90, 65.37, 56.50.

\section{Synthesis of the $\mathbf{N}^{1}, \mathbf{N}^{4}$-di-tert-butyl-2,3-dihydroxyfumaramide 11.}

The mixture of esters 2 ( $1.76 \mathrm{~g}, 0.01 \mathrm{~mole})$ and 2-methylpropan-2-amine $(0.73 \mathrm{~g}, 0.01 \mathrm{~mole})$ was stirred at room temperature for 8 hours. After completion (TLC analysis), compound 11 was separated as white crystals by crystallization 
from EtOAc and filtration. Yield: 1.81g, 70\%. Spectrum ${ }^{1} \mathrm{H}$ NMR: $1.23 \mathrm{~s}\left(18 \mathrm{H}, 6 \mathrm{CH}_{3}\right), 5.0-6.3 \mathrm{br} \mathrm{s}(2 \mathrm{H}, 2 \mathrm{OH}), 7.61 \mathrm{~s}$ (2H, 2 NH). Spectrum ${ }^{13}$ C NMR: 173.5, 160.60, 50.89, 28.76.

\section{Synthesis of the $(E)-3-(1 \mathrm{H}-b e n z o[d]$ imidazol-2-yl)-2,3-dihydroxyacrylic acid 12.}

The mixture of acid 1 (1.48 g, 0.01 mole) and $o$-phenylenediamine (1.08 g, 0.01 mole) were refluxed for 18 hours in $20 \mathrm{ml}$ of $\mathbf{4} \mathrm{N}$ hydrochloric acid. The reaction mixture was cooled, the crystalline dihydrochloride separated by filtration. Product was treated with hot $20 \%$ aq $\mathrm{NH}_{4} \mathrm{OH}$ and washed with water. Acidification of the ammoniacal filtrate with $\mathrm{AcOH}$ gave the corresponding monobenzimidazole. Attempts to recrystallize the product from EtOH gave a gum 12, which solidified on standing. Yield: $1.07 \mathrm{~g}, 49 \%$. It decomposes at $250{ }^{\circ} \mathrm{C}$. Spectrum ${ }^{1} \mathrm{H}$ NMR: $5.0-6.3 \mathrm{broad} \mathrm{s}(3 \mathrm{H}$, 2OH, NH), 7.15-7.6 m (2H, arom), 7.7-7.81 m (2H, arom), $10.06 \mathrm{~s}\left(1 \mathrm{H}, \mathrm{CO}_{2} \mathrm{H}\right)$.

\section{Synthesis of the (E)-1,2-di(1H-benzo[d]imidazol-2-yl)ethene-1,2-diol 13.}

The mixture of acid 1 (1.48 g, 0.01 mole) and $o$-phenylenediamine ( $2.16 \mathrm{~g}, 0.02$ mole) were refluxed for 36 hours in $50 \mathrm{ml}$ of $5 \mathrm{~N}$ hydrochloric acid in an oil bath at $135^{\circ} \mathrm{C}$ under $\mathrm{N}_{2}$. The mixture was cooled in an ice bath to separate the $\mathrm{HCl}$ salts of the bisbenzimidazole 13. In this case the crude product was treated with hot sodium bicarbonate solution in place of aqueous ammonia. Recrystallization of product from ethylene glycol or EtOH in both cases gave a gum 13, which solidified on standing. Yield: $0.876 \mathrm{~g}, 30 \%$. It decomposes at $250{ }^{\circ} \mathrm{C}$. Spectrum ${ }^{1} \mathrm{H}$ NMR: $4.7-6.9 \mathrm{br} \mathrm{s}(6 \mathrm{H}, 4 \mathrm{OH}$, $2 \mathrm{NH}), 7.16-7.68 \mathrm{~m}(8 \mathrm{H}$, arom).

\section{References}

[1]. Дука, Г.; Гаина, Б.; Ковалева, О.; Ковалев, В.; Гонца, М. Экологически чистое винодельческое производство. Ştiința, 2004.

[2]. Hough, L.; Jones, J. K. N. Nature, 1951, 167, 180.

[3]. Sychev, A.; Duka, G. G. Sadovod. Vinograd. Vinodel. Mold. 1985, 12, 34.

[4]. Nelson, Eric L., Richard L. United States Patent 4490389

[5]. Verachtert, H. United States Patent 4311598

[6]. Michelson, A.M.; Rotter, P. United States Patent 4088595

[7]. Irimi, S.; Molnar A.; Gabor J.; Toke L. United States Patent 5060672.

[8]. D’Amico, A.; Chiesa, F.; Montaldi, D.; Quarenghi, F. Bull. Soc. Chim. Fr. 1962, 101, 903.

[9]. Gonța M., Duca M., Porubin D., Voloc N. Anale Ştiinţifice ale USM, Chişinău 2003, 419-425

[10]. Porubin Diana. Chemistry Journal of Moldova. 2007, 2, 3-7.

[11]. Porubin, D.; Hecht, S. S.; Li, Zh.; Gonta, M.; Stepanov, I. Journal of Agricultural and Food Chemistry, 2007, 55, 7199-7204.

[12]. Bellec, N.; Garrido Montalban, A.; Williams D. B. G.; Cook, A.S.; Anderson, M. E.; Xidong Feng, Barrett, A. G. M.; Hoffman, B.M. J. Org. Chem. 2000, 65, 1774-1779.

[13]. Goldberg, D.P.; Michel, S.L. J.; White, A.J. P.; Williams, D. J.; Barrett, A. G. M. ; Hoffman B. M. Inorg. Chem. 1998, 37, 2100-2101.

[14]. Dreher, D.D. United States Patent 0090668.

[15]. Hartree E. F., J. Am. Chem. Soc., 1953, 75, 6244-6249.

[16]. Goodwin S., Witkop B., J. Chem. Soc., 1954, 76, 5599-5603.

[17]. Brand-Williams, W.; Cuvelier, M.E.; Berset, C. Lebensm. Wiss. Technol. 1995, 28, 25-30. 